\title{
Shear Resistance of Reinforced Aerated Concrete Slabs: Prediction via Artificial Neural Networks
}

\author{
Derya Bakbak ${ }^{\mathrm{a}}$, Ahmet Emin Kurtoğlu b,* \\ ${ }^{a}$ The Grand National Assembly of Turkey (TBMM), 06534, Çankaya, Ankara, Turkey \\ ${ }^{b}$ Department of Civil Engineering, Istanbul Rumeli University, 34570, Silivri, Istanbul, Turkey
}

Manuscript Received March 5, 2019; Accepted May 6, 2019

\begin{abstract}
Autoclaved aerated concrete (AAC) provides advantageous material characteristics such as high thermal insulation and environmentally friendly properties. Besides its non-structural applications, AAC is being considered as a structural material due to its characteristics such as lighter weight compared to normal concrete. In this study, main focus is to test the usability of artificial neural networks (ANNs) in predicting the shear resistance of reinforced AAC slabs. A large experimental database with 271 data points extracted from eleven sources is used for ANN training and testing. Network training is accomplished via multi-layer backpropagation algorithm. Based on random selection, the dataset is partitioned into two portions, $75 \%$ for network training and $25 \%$ is for testing the validity of the network. Different models with a varying number of hidden neurons are developed to capture the network with optimum hidden neuron numbers. The results of each model are presented in terms of correlation coefficient $\left(R^{2}\right)$ and mean squared error $(M S E)$. Results suggest that the ANN model with seven hidden neurons is the simplest model with most accurate predictions and ANNs can provide excellent prediction ability with insignificant error rates.
\end{abstract}

Keywords: Artificial neural networks; autoclaved aerated concrete; reinforced concrete slab; shear strength; modelling.

\section{Introduction}

Being a porous and light building material, autoclaved aerated concrete (AAC) is made of cement or lime mortar containing air voids entrapped in the matrix by means of an expansion agent. It has been used in the construction industry for non-structural and structural applications since mid-1920s. By volume, $70-80 \%$ of AAC consists of air voids, resulting in lower density which minimizes the design cost [1]. AAC is considered to be environmentally friendly material as it reduces $70 \%$ and $40 \%$ energy per material volume as compared to normal concrete and bricks, respectively. It also provides high thermal insulation [2, 3].

Production of AAC panel elements with reinforcement can offer an alternative for low-rise precast construction. 60\% of new building constructions in Europe are built with different types of AAC elements [4]. In the housing industry in China, reinforced AAC materials for exterior walls are preferred to other materials [4].

Shear resistance of reinforced normal concrete or AAC slabs without shear reinforcement is a complex phenomenon. It is known that the shear resistance depends not only on the concrete properties but also on the shear-span-to-depth $(a / d)$ ratio as well as the presence of tensile reinforcement (Fig. 1). Aroni and Cividini

* Corresponding author. Tel.:+90-212-866-0101

E-mail address: aemin.kurtoglu@ rumeli.edu.tr

https://doi.org/10.29187/jscmt.2019.38 
(1989) proposed a formulation (Eq. 1a, Eq.1b) for the shear strength of reinforced AAC slabs with a modification to the formulation available for normal concrete slabs [5]. Fig. 2 shows a typical shear resistance test setup of reinforced AAC slab.

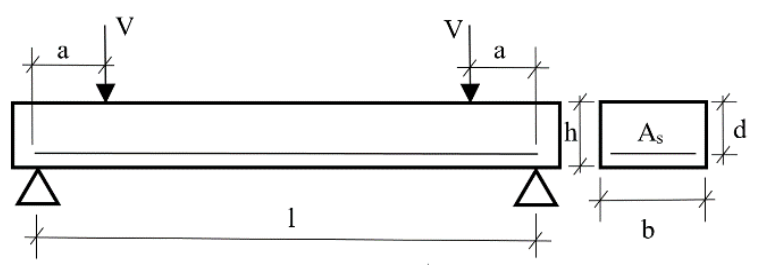

Fig. 1. Typical test setup

$$
\begin{array}{ll}
\tau_{u}=0.035 f_{c}+1.163 \rho(d / a)-0.053 ; & \text { within the normal range } \\
\tau_{u}=0.039 f_{c}+0.82 \rho(d / a)-0.075 ; & \text { outside the normal range }
\end{array}
$$

Where $\tau_{u}$ is the ultimate shear stress in $\mathrm{MPa}\left(\tau_{u}=V_{u} / b d\right), f_{c}$ is the compressive strength of AAC in MPa, $\rho$ is reinforcement ratio $\left(100 A_{s} / b d\right), d$ is the effective depth in $\mathrm{mm}, a$ is the shear span in $\mathrm{mm}$.

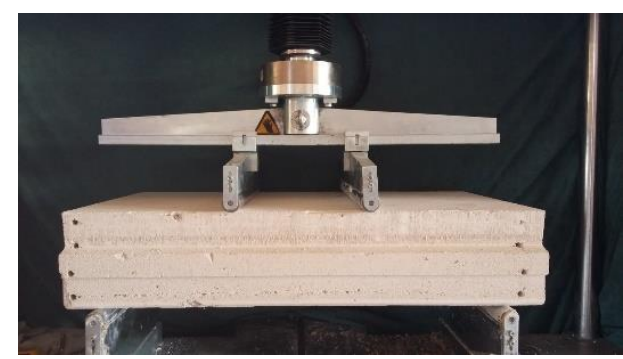

Fig. 2. Test setup

To date, research related to ANN modeling has aspired to gain insight into estimation possibility and revealing the relationship between concrete properties and components. This study focuses on developing an ANN based model expressed in explicit format involving all concrete and reinforcement properties.

\section{Data Collection}

The collected experimental database contains 271 data points extracted from previously published papers [615], reported in [5]. Table 1 summarizes the origins and product types for the tests. All data points were included in the modeling process. Data inputs are $f_{c}$ (compressive strength), $d / a$ (span-to-depth ratio) and $\rho$ (reinforcement ratio), the output is $\tau_{u}$ (ultimate shear stress, $V / b d$ ). Table 2 presents the statistical variations of input and output parameters. Some specimens contained compression reinforcement consisting of two or three bar. Possible contributions of these bars in shear strength have been neglected.

Table 1 References and types of test product

\begin{tabular}{lll}
\hline $\begin{array}{l}\text { Series } \\
\text { No. }\end{array}$ & Reference & Product type \\
\hline 1 & Bernon [14] (France) & Siporex \\
2 & Blaschke [13] (Germany) & Ytong \\
3 & Briesemann [12] (Germany) & Hebel \\
4 & Cividini [11] (Yugoslavia) & Siporex, Ytong \\
5 & Dalby [10] (Sweden) & Siporex \\
6 & Edgren [10] (Sweden) & Siporex \\
7 & Kanoh '66 [9] (Japan) & Siporex \\
8 & Kanoh '69 [8] (Japan) & Hebel \\
9 & Matsamura [7] (Japan) & ALC \\
10 & Newarthill [6] (UK) & Siporex \\
11 & Regan [15] (UK) & Durox \\
\hline
\end{tabular}


Table 2 Statistics of experimental data

\begin{tabular}{lllll}
\hline & $\begin{array}{l}f_{c} \\
(\mathrm{MPa})\end{array}$ & $d / a$ & $\rho$ & $\begin{array}{l}\tau_{u} \\
(\mathrm{Mpa})\end{array}$ \\
\hline Minimum & 2.3 & 0.08 & 0.12 & 0.107 \\
Maximum & 7.8 & 0.766 & 1.349 & 0.836 \\
Mean & 3.78 & 0.24 & 0.41 & 0.24 \\
Standard deviation & 1.31 & 0.16 & 0.26 & 0.14 \\
Coeff. of variation & 0.35 & 0.66 & 0.62 & 0.56 \\
\hline
\end{tabular}

\section{Overview of Artificial Neural Networks}

Artificial neural networks are computational models that can give answers to demanding questions by simulating the biological nervous system. An ANN has powerful characteristics of learning and processing the data, and it has the potential for the solution of engineering problems [16].

An ANN consist of highly connected neurons aligned in layers. Most commonly used ANN architectures are feed-forward multilayer perception network and multilayer back-propagation network. According to [17], back propagation algorithm is the most popular paradigm in which the model training is processed within the neural networks with a set of input-output data. Back propagation algorithm generally consists of an input layer, one or more hidden layers and an output layer (Fig. 3). In the output layer, the error between desired and calculated values is compared and then propagated back to the network where updated weights are assigned. Then, the process is repeated for the number of epochs until a pre-determined accuracy rate is achieved. When the network training is terminated, after validation, the network is then used for testing stage in which a brand new dataset is substituted to the network.

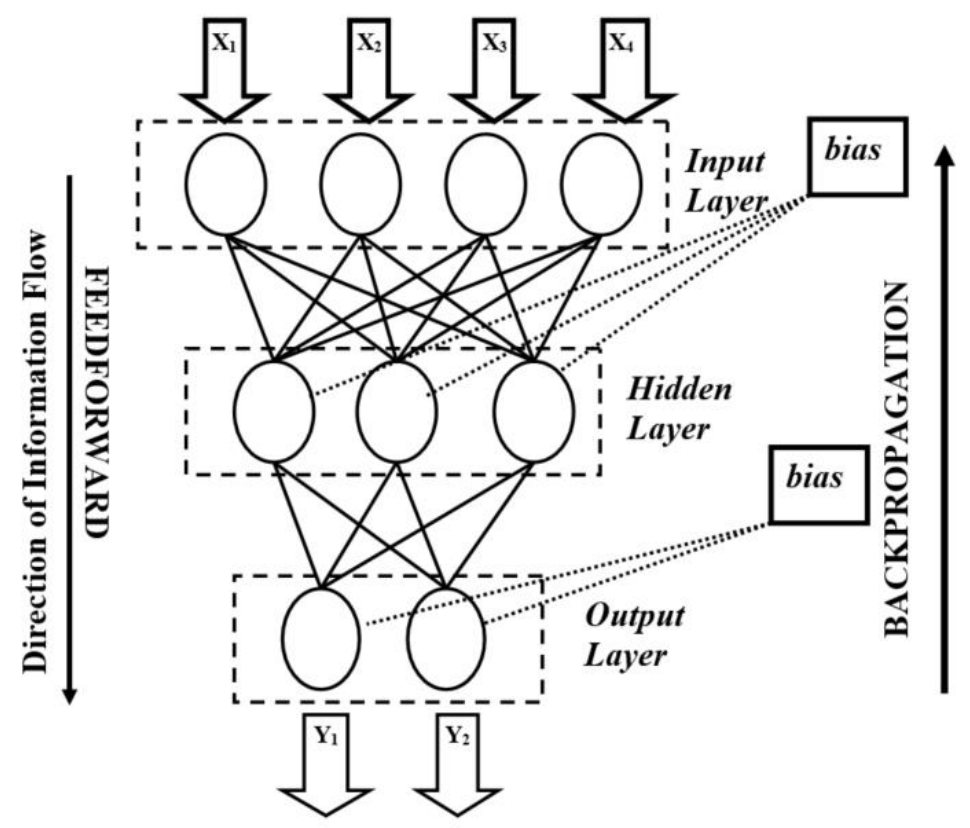

Fig. 3. Typical ANN structure [18]

\section{Numerical Application}

The main purpose of this study is to estimate the results of shear strength of experimentally tested aerated concrete slabs. For this purpose, a dataset containing 271 data points is extracted from literature and used for training and testing the ANN models. Back propagation algorithm is implemented for training the ANN models. The data is divided into two portions ( $75 \%$ as training set, $25 \%$ as testing set) based on random selection. Statistical norms (correlation coefficient, $R^{2}$ and mean squared error, MSE) are used for performance evaluation. Correlation coefficient $\left(R^{2}\right)$ measure the relationship between predicted and experimental data, i.e., $R^{2}=1$ means significant correlation and $R^{2}=0$ means no correlation. Eq. 2 and Eq. 3 are used for calculating $R^{2}$ and $M S E$, respectively. 


$$
\begin{gathered}
R^{2}=1-\left(\frac{\sum_{i=1}^{N}\left(o_{i}-t_{i}\right)^{2}}{\sum_{i=1}^{N}\left(o_{i}-o^{\prime}\right)^{2}}\right) \\
M S E=\frac{\sum_{i=1}^{N}\left(o_{i}-t_{i}\right)^{2}}{N}
\end{gathered}
$$

where $o_{i}$ is the experimental value of $i t h$ data, $t_{i}$ is the predicted value of $i t h$ data, $N$ is the number of data used for training and testing of ANN models.

Proper determination of hidden neuron number is of paramount importance as it has a strong influence on the network stability, e.g., over-fitting or under-fitting of the network. To overcome this concern, some software applications provide grid search to find the optimum neuron number. In this study, the number of hidden neurons is changed for each ANN model and, $R^{2}$ and mean squared error (MSE) results are evaluated for each hidden neuron number (Fig. 4 and Fig. 5). It is observed from the Fig4. And Fig. 5 that, although increasing the number of hidden neurons does not change $R^{2}$ results significantly, $M S E$ values vary with changing the number of hidden neurons. Although the model with fifteen hidden neurons yields slightly lower MSE values and almost the same correlation coefficient, the model with seven hidden neurons was selected for simplicity and due to insignificant performance difference between models.

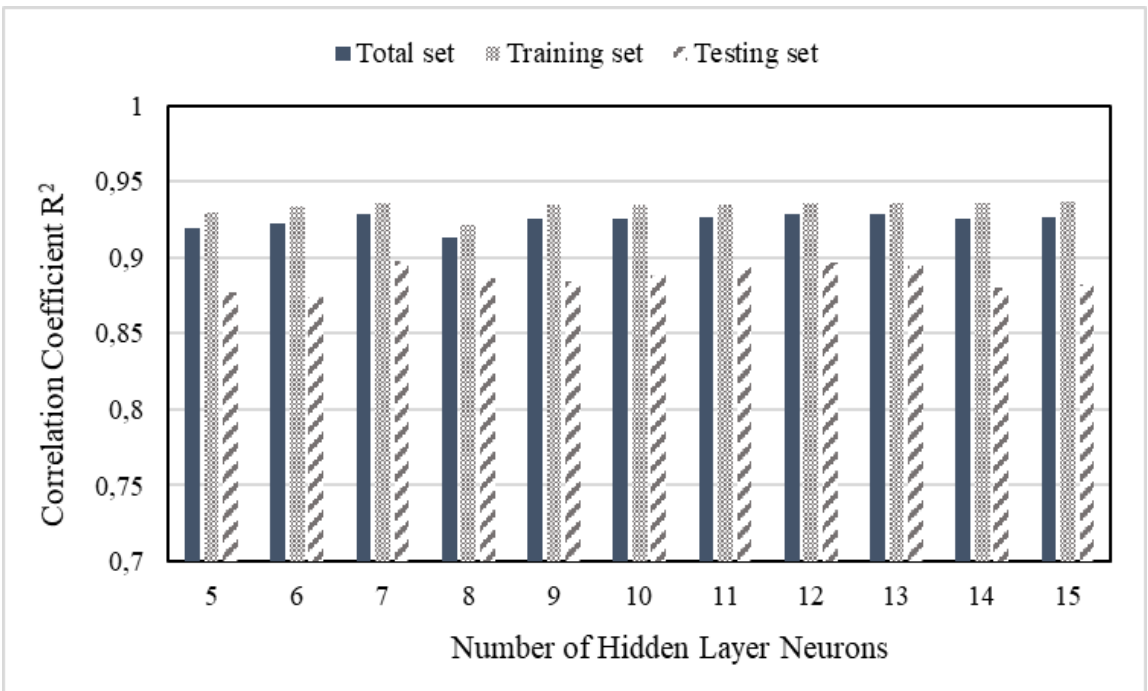

Fig. 4. Correlation Coefficient $\left(R^{2}\right)$ versus Number of Hidden Layer Neurons

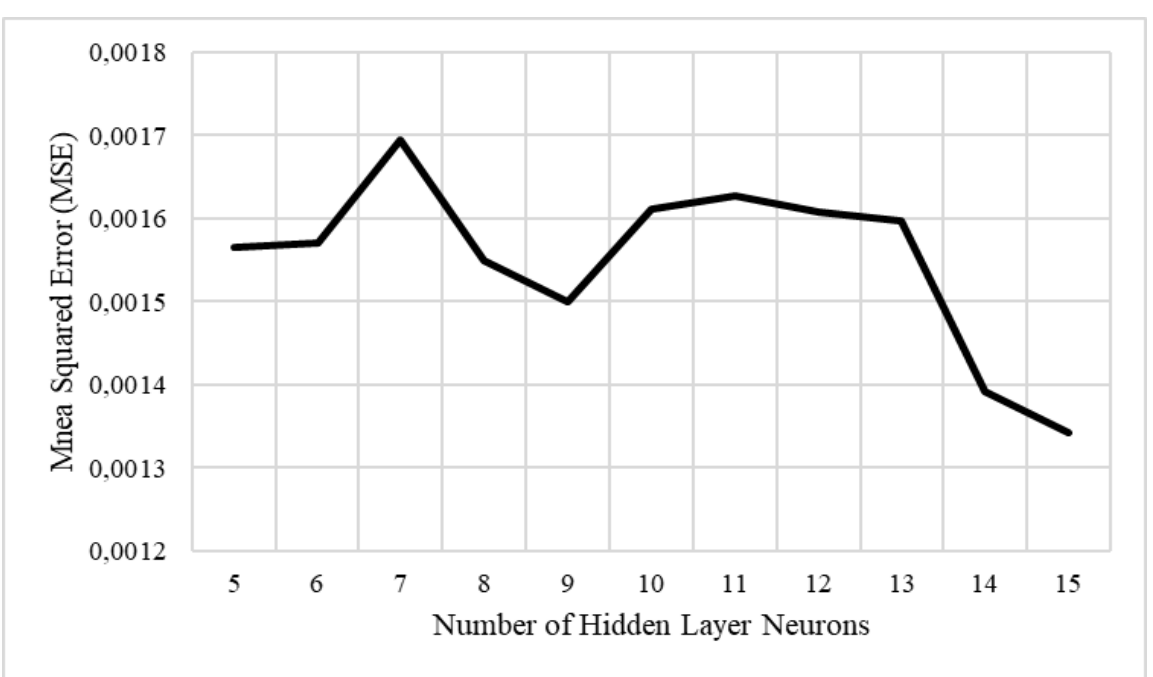

Fig. 5. Mean Squared Error (MSE) versus Number of Hidden Layer Neurons 
Eq. 4 gives the explicit form of the proposed ANN model, in which $I N_{i}$ stands for the $i_{t h}$ input layer, $H L_{\mathrm{i}}$ stands for the $i_{t h}$ hidden layer and $O U T$ is the output layer.

$f(x)=1 /\left(1+e^{-x}\right)$

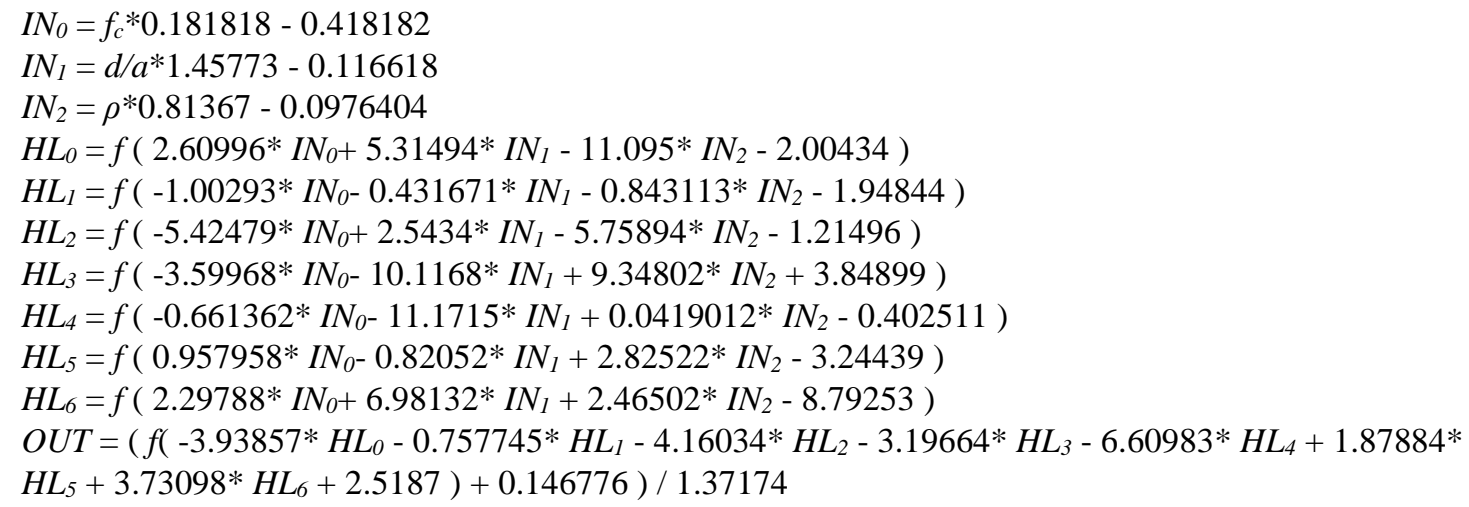

Fig. 6 compares the estimated and experimental values and their differences for testing and training dataset. It is apparent that the deviations are significantly small both for training and testing datasets.

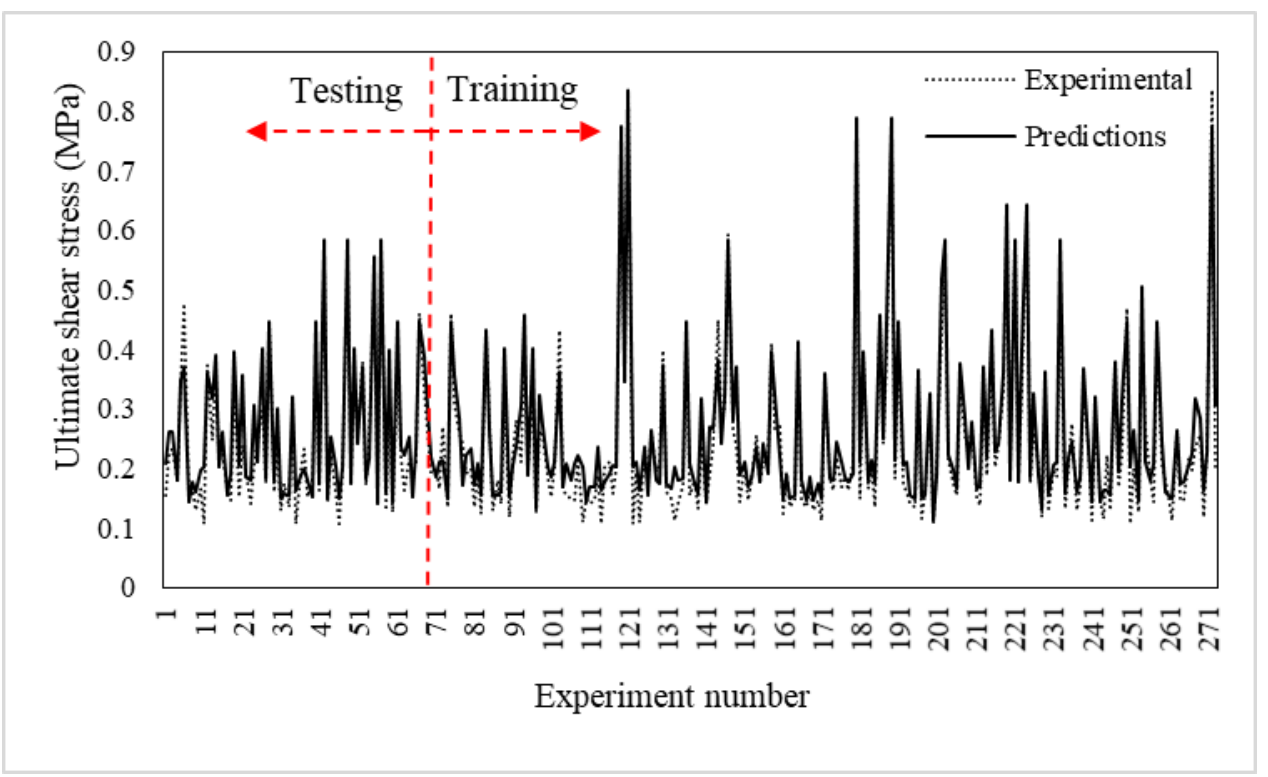

Fig. 6. Experimental versus predictions of ANN model

According to [19], if the correlation coefficient $R^{2}$ is greater than 0.8 and the error values are at a desirable range, there is a strong correlation between predicted and real values. Regarding Fig. 7, proposed ANN model has a $R^{2}$ value of $0.937,0.882$ and 0.926 for the training, testing and whole set, respectively, and the error is acceptable. 


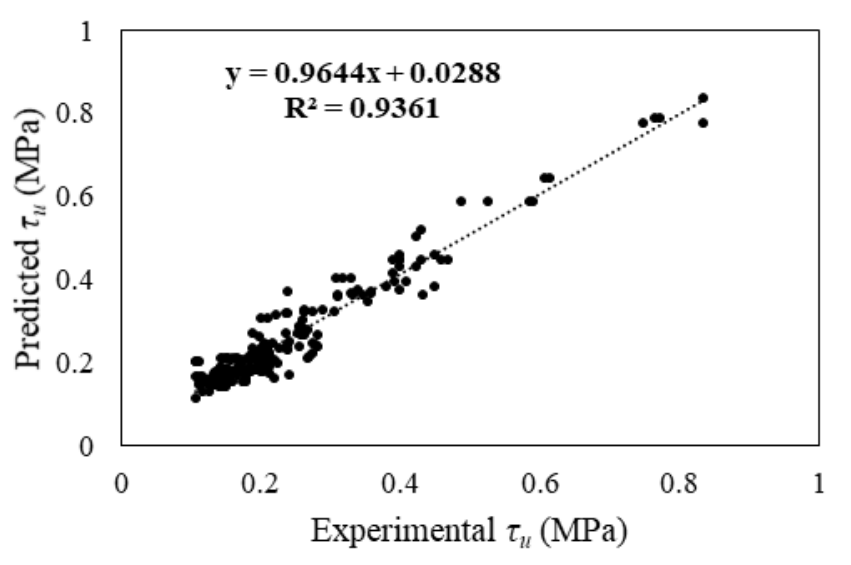

a. Training data

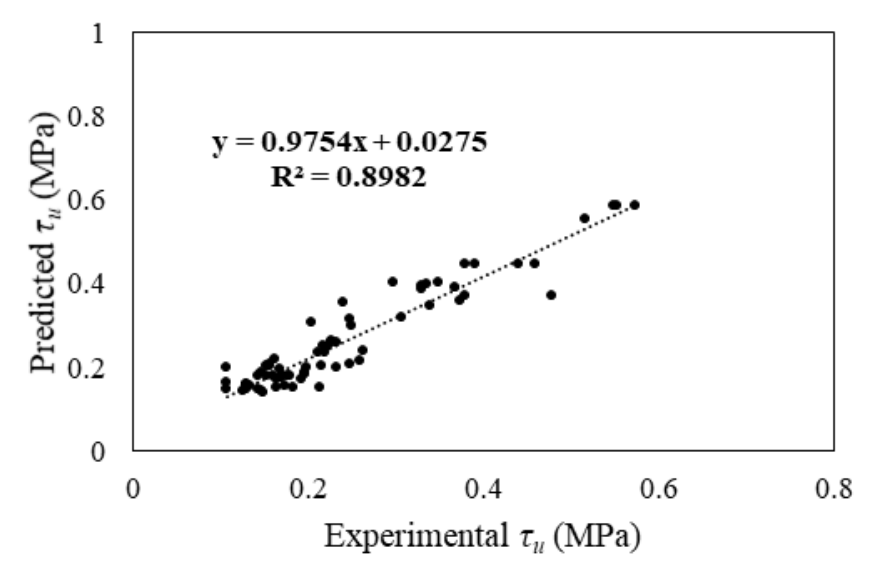

b. Testing data

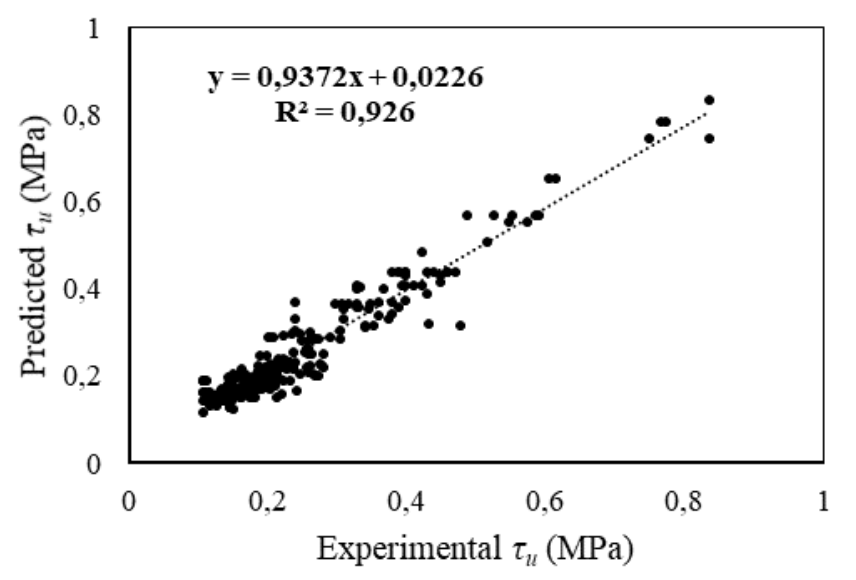

c. Whole data

Fig. 7. Experimental versus predicted data

\section{Conclusions}

In this study, we provide ANNs model to estimate the ultimate shear resistance of reinforced autoclaved aerated concrete slabs by the use of an experimental database reported in the literature. The dataset is partitioned into two sets for the purpose of training and testing the developed models. A different number of neurons is assigned to each model to avoid over-fitting and under-fitting problems. Each model is analyzed statistically to determine the prediction performance. For this, mean squared error $(M S E)$ and correlation coefficient $\left(R^{2}\right)$ are used. In this regard, conclusions drawn from this study are:

- Proper selection of hidden neuron numbers plays an important role in prediction performance i.e., $R^{2}$ and 
$M S E$ values vary considerably as the number of hidden neurons change.

- ANN model with seven hidden neurons yields the most accurate results $\left(R^{2}=0.928, M S E=0.001695\right)$. Although model with fifteen hidden neurons yields slightly lower $M S E$ values, model with seven neuron was selected for the sake of simplicity. ANN model is expressed as a discrete formulation format. Estimations are quite close to experimental values both for training and testing sets.

- In general, proposed ANN models yield high accuracy and have applicability with respect to predicting the shear resistance of AAC slabs. Moreover, it is shown that the ANNs can be an important alternative to provide predictive models based on inhomogeneous data samples.

\section{References}

1. A. Thongtha, S. Maneewan, C. Punlek, and Y. Ungkoon, Investigation of the compressive strength, time lags and decrement factors of AAC-lightweight concrete containing sugar sediment waste. Energy and Buildings, 84(2014).

2. X. Qu and X. Zhao, Previous and present investigations on the components, microstructure and main properties of autoclaved aerated concrete-A review. Construction and Building Materials, 135(2017).

3. A. Bonakdar, F. Babbitt, and B. Mobasher, Physical and mechanical characterization of fiberreinforced aerated concrete (FRAC). Cement and Concrete Composites, 38(2013).

4. A. Taghipour, et al., Seismic behavior of reinforced autoclaved aerated concrete wall panels. ce/papers, 2(2018) 4.

5. S. Aroni and B. Cividini, Shear strength of reinforced aerated concrete slabs. Materials and Structures, 22(1989) 6.

6. N. Edgren, Shear tests on Siporex slabs (Newarthill Factory, UK)'. unpublished report (Internationella Siporex AB, Central Laboratory, 1981-82).

7. A. Matsumura, Shear strength and behavior of reinforced autoclaved lightweight cellular concrete members. Trans. Architect. Inst. Jpn, 343(1984).

8. Y. Kanoh, Report of Hebel research'. unpublished report (Meiji University, 1969).

9. Y. Kanoh, Shear strength of the reinforced autoclaved lightweight concrete one-way slabs'. Proceedings of Research Papers of the Faculty of Engineering, Meiji University, (1966) 21.

10. N. Edgren, Shear tests on Siporex slabs (Dalby Factory, Sweden)'. unpublished report (Internationella Siporex AB, Central Laboratory, 1979).

11. B. Cividini, Ispitivanje granicne nosivosti armiranih ploca od plinobetona (Investigation of bearing capacity of reinforced aerated concrete slabs). Proceedings of 17th JUDIMK Congress, Sarajevo, October, (1982).

12. D. Briesemann, Die schubtragfähigkeit bewehrter platten und balken aus dampfgehärtetem gasbeton anch versuchen. (1980).

13. R. Blaschke, Shear load behaviour of AAC reinforced units of high compressive strength (GB 6.6)'. unpublished report (Ytong Research Laboratory, Schrobenhausen, 1988), (1988).

14. N. Edgren, Shear tests on Siporex slabs (Bernon Factory, France)'. unpublished report (Internationella Siporex AB, Central Laboratory, 1979-80).

15. P. Regan, Shear in reinforced aerated concrete. International Journal of Cement Composites and Lightweight Concrete, 1(1979) 2.

16. S. Haykin and N. Network, A comprehensive foundation. Neural networks, 2(2004) 2004.

17. R. Lippmann, An introduction to computing with neural nets. IEEE Assp magazine, 4(1987) 2.

18. J. Zupan and J. Gasteiger, Neural Networks for Chemists - An Introduction, VCH: Weinheim, 1993.

19. G.N. Smith, Probability and statistics in civil engineering. Collins Professional and Technical Books, 244(1986). 